Sensors 2014, 14, 1-x manuscripts; doi:10.3390/s140x0000x

\title{
High performance electrochemical sensor based on task specific ionic liquid mixed palm shell activated carbon for trace level $\mathrm{Cd}$ (II) detection
}

\author{
Ahmed Abu Ismaiel, Mohamed Kheireddine Aroua* and Rozita Yusoff \\ Chemical Engineering Department, University of Malaya, Kuala Lumpur, Malaysia; E-Mails: \\ abu_ismaiel@hotmail.com (A.A.I.); mk_aroua@um.edu.my (M.K.A.); ryusoff@um.edu.my (R.Y.) \\ * Author to whom correspondence should be addressed; E-Mail: mk_aroua@um.edu.my; \\ Tel.: +603 7967 5206; Fax: +6037967 5319.
}

Received: / Accepted: / Published:

\begin{abstract}
In this study, the combination of activated carbon with task specific ionic liquids has resulted in a unique new generation paste in which the traditional components have been replaced with alternate materials. In this study, palm shell activated carbon modified with trioctylmethylammonium salicylate was used as a novel electrode component for the potentiometric determination of cadmium ions in water samples. The proposed potentiometric sensor has good operating characteristics when used to determine $\mathrm{Cd}(\mathrm{II})$, including a relatively high selectivity; a Nernstian response in a working concentration range of $1.0 \times 10^{-9}$ to $1.0 \times 10^{-2} \mathrm{M}$, with a detection limit of $1 \times 10^{-10} \mathrm{M}$ and a slope of 30.90 $\pm 1.0 \mathrm{mV} /$ decade; and a fast response time $(\sim 10 \mathrm{~s})$. The proposed sensor can also be used for at least two months without considerable changes in its response characteristics. No significant changes in the electrode potential were observed when the $\mathrm{pH}$ was varied over the range of 4-9. Additionally, the proposed electrodes have been successfully used for the determination of the cadmium contents of real samples without a significant interaction from other cationic or anionic species.
\end{abstract}

Keywords: Ion selective electrodes; potentiometric sensors; activated carbon; trioctylmethylammonium salicylate; task specific ionic liquids; cadmium (II) detection. 


\section{Introduction}

According to the World Health Organization (WHO) guidelines, the maximum permissible concentration of cadmium in drinking water is $0.003 \mathrm{mg} / \mathrm{L} \mathrm{[1]}$. Cadmium can accumulate in the human body, especially in the kidneys, and cause dysfunction; therefore, there is an increasing interest in the determination of cadmium ion content in drinking water due to its toxicity to human health [2]. Several analytical techniques, including, flame atomic absorption spectrometry (FAAS) [3], electrothermal atomic absorption spectrometry (ETAAS) [4 ], inductively coupled plasma mass spectrometry (ICPMS) [5], atomic fluorescence spectrometry (AFS) [6], and high-performance liquid chromatography (HPLC) [7] have been applied for the determination of trace amounts of cadmium in analytical samples. Although these techniques provide accurate results, they have several disadvantages, such as high apparatus cost, complex operation, high operation and maintenance costs, and the requirement of well-controlled experimental conditions. For these reasons, one of the most favourable techniques for cadmium ion determination is the potentiometric method.

The determination of low-level contaminants in ground water has become a major issue during the last several decades. The necessity of monitoring pollutant levels in aqueous solution is becoming increasingly important with time. Unfortunately, the continuous monitoring of water pollutants in the field requires portable fast response sensors with sufficient sensitivity and high selectivity. For these reasons, the determination of pollutants in ground water requires new and improved techniques for rapid and low-cost monitoring. Ion selective electrodes (ISEs) are potentiometric sensors used to measure some of the most critical analytes in environmental laboratory and point-of-care analysers. Despite their easy fabrication, simple usage, and low cost, ISEs suffer from low response sensitivity, interference by a number of metal ions and short lifetimes. As a result, the development of new ISE materials that can address some of these limitations is a worthwhile and challenging topic of research and huge progress in the improvement of the detection limit made during the last decade.

Activated carbon is a micro porous material with a large internal surface area and porosity. Many different carbonaceous materials can be used as raw materials for the production of activated carbon. Generally, the raw materials have high carbon and low inorganic contents, such as wood, coal, peat, and agricultural waste. Oil-palm shell is an agricultural by-product from palm-oil processing mills in many tropical countries, including Malaysia. Palm shells have been used to produce activated carbon due to their easy available, low cost, and high carbon and low inorganic contents. Palm shell activated carbon is the most popular and cheapest form of activated carbon, with a wide variety of electrochemical applications due to its extended surface area, microporous structure, high adsorption capacity, and high surface reactivity.

Task-specific ionic liquids are a unique subclass of ionic liquids that possess a potential spectrum of utility extending far beyond that of more conventional ILs [8]. The physical and chemical properties (e.g., high polarity, conductivity, viscosity, Lewis acidity, and hydrophobicity) of task specific ionic liquids can be tuned by varying the structure of the component ions to obtain the desired properties. Ionic liquids (ILs) as well as task specific ionic liquids (TSILs) are finding an increasing number of applications in electrochemistry. Their application in analytical chemistry is due to their unique 
properties, such as negligible vapour pressure, good thermal stability, tunable viscosity, and miscibility with water and organic solvents, as well as their good extractability for various organic compounds and metal ions [9]. Recently, novel ion selective sensors based on ILs have been developed [10,11].

The groundwater aquifer is the most important fresh water source in the Gaza Strip; however, it is severely polluted, mainly by salt water, nitrates, heavy metals, and other pollutants. Several domestic wells have shown high cadmium concentrations [12]. These wells are located in regions with intense agriculture, wastewater treatment plants, and solid waste dumping sites. The main contamination sources are the unregulated discharge of domestic and industrial solid waste, water waste, and agricultural waste from fertilizers and pesticides.

Classical methods have been used to determine the contents of these pollutants, such as gravimetry, spectrophotometry, and chromatography. These methods are time-consuming and tedious and require experts. Moreover, they produce additional waste and are expensive. In addition, these methods cannot be used for all samples and are largely unavailable in Gaza.

The ultimate goals of this study are to increase the sensitivity and selectivity of the proposed electrodes by minimizing the previously mentioned undesirable electrode processes. Additionally, the application of plasticizer-free electrodes can eliminate the leaching of the electrode solvent and sensing components, improving the electrode lifetime. The main objective of this study is to develop and evaluate the performance of novel ion selective electrode based on trioctylmethylammonium salicylate (TOMAS) as both an ionophore and plasticizer for the determination of Cd (II) in aqueous solutions. The research will include preparation of the ISE, determination of their analytical characteristics, and their applications in the monitoring of ion concentration in ground water samples.

\section{Experimental Section}

\subsection{Chemicals and Reagents}

Analytical reagent grade chemicals and distilled, de-ionized water were used to prepare all aqueous solutions. Commercially available granular palm shell activated carbon (PSAC) was provided by Bravo Green Sdn Bhd, Malaysia. Activated carbon powder with particle sizes $<40 \mu \mathrm{m}$ were used throughout the potentiometric experiments. The $\mathrm{pH}$ of the solutions was adjusted by adding appropriate amounts of concentrated hydrochloric acid $(1 \mathrm{M} \mathrm{HCl})$ and/or sodium hydroxide (2M $\mathrm{NaOH}$ ). Metal salts were purchased from Merck, and aqueous metal solutions were prepared by dissolving appropriate quantities of metal salts in de-ionized water. Sodium salicylate was purchased from R\&M chemicals. Trioctylmethylammonium chloride (Aliquat ${ }^{\circledR} 336$ ) and 2-nitrophenyl octyl ether (NPOE) were purchased from Sigma-Aldrich. The plasticizers bis(2-ethylhexyl)adipate (DOA), bis(2-ethylhexyl) phthalate (DOP), tris(2-ethylhexyl) phosphate (TOPh), bis(2-ethylhexyl) sebacate (DOS), butyl phosphate (BPh), dibutyl phosphate (DBPh), and tributyl phosphate (TBPh) were purchased from Merck.

\subsection{Apparatus}

All potentiometric measurements were made using a $\mathrm{pH} /$ ion meter (Metrohm-781, Germany) and $\mathrm{pH}$ Module (Metrohm-867), permitting real-time potential data collection using the proposed electrode 
in conjunction with a double junction $\mathrm{Ag} / \mathrm{AgCl}$ reference electrode. The temperature of the cell holder was maintained at $25{ }^{\circ} \mathrm{C}$ and measured under constant stirring with a magnetic stirring bar at a rate such that no bubbles or vortexes were formed.

The electrode surfaces morphology and its elemental analysis were obtained using field emission scanning electron microscope AURIGA cross beam workstation (Carl Zeiss) equipped with EDAX (AMETEK, advanced microanalysis solutions) at an accelerating voltage of $25 \mathrm{kV}$.

Metal ion sample concentration was analyzed by inductively coupled plasma optical emission spectrometer ICP-OES. (PerkinElmer, model ICP optima 7000DV). Metal ions standards with concentration $1 \mathrm{ppm}, 5 \mathrm{ppm}, 10 \mathrm{ppm}, 20 \mathrm{ppm}, 40 \mathrm{ppm}, 60 \mathrm{ppm}, 100 \mathrm{ppm}$ and, $200 \mathrm{ppm}$ were used to calibrate the instrument each time before starting the analysis of the samples.

\subsection{Preparation of trioctylmethylammonium salicylate (TOMAS)}

Trioctylmethylammonium salicylate was synthesized according to [13] as a slightly yellowish viscous liquid (yield: 85\%), analyzed by nuclear magnetic resonance (NMR) and Fourier transform infrared spectroscopy (FTIR), then used without further purification. The reaction is illustrated in Fig. 1. Aliquat ${ }^{\circledR} 336(0.1 \mathrm{~mol})$ was mixed with an equal molar amount of sodium salicylate in $200 \mathrm{~mL}$ of acetone. The mixture was shaken for $5 \mathrm{~h}$ and left overnight. The precipitate was then filtered off, and acetone was evaporated from the filtrate using a rotary evaporator. The obtained RTIL was rinsed 10 times with a large amount of distilled water, and the remaining liquid was heated to $100{ }^{\circ} \mathrm{C}$ under reduced pressure for $5 \mathrm{~h}$. A clear, slightly yellowish, viscous liquid (TOMAS) was obtained. TOMAS is clear liquid with a density of slightly less than $1 \mathrm{~g} \mathrm{~cm}^{-3}(0.945)$. TOMAS is immiscible with water. FTIR, ${ }^{1} \mathrm{H}$ and ${ }^{13} \mathrm{C}$ NMR spectra confirmed the identity of the obtained TOMAS.

Figure 1. Synthetic pathway for trioctylmethylammonium salicylate (TOMAS).
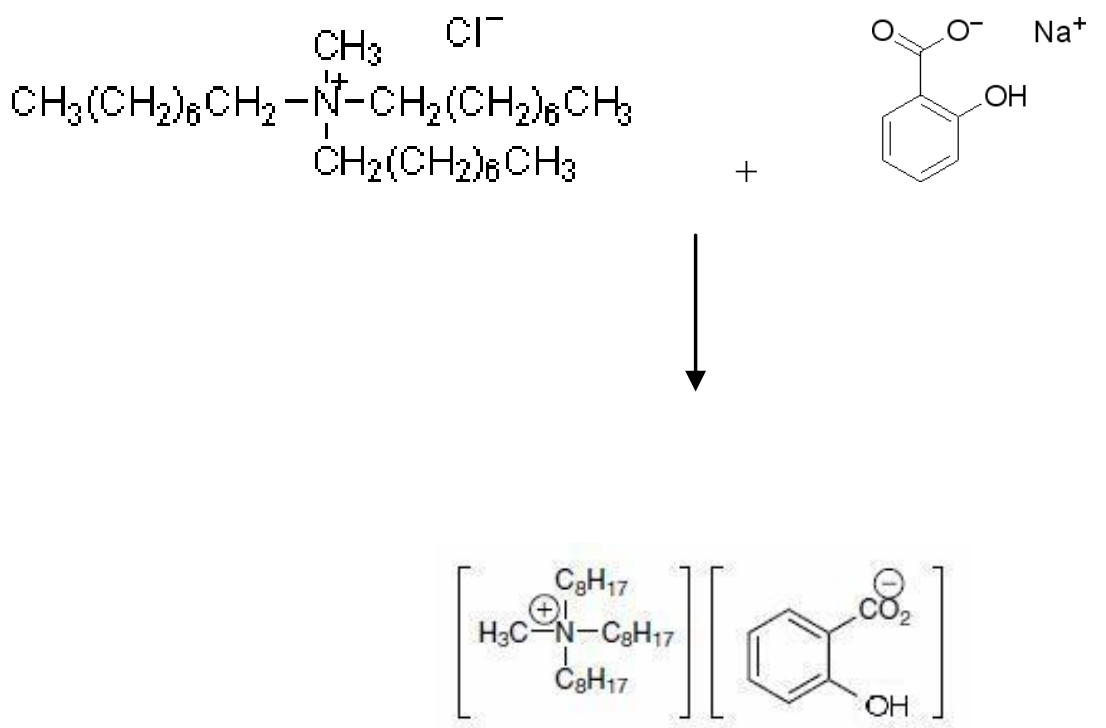


\subsection{Preparation of carbon paste electrode based on TOMAS and potential measurements}

Modified palm shell activated carbon paste was prepared by hand mixing the determined quantities of palm shell activated carbon powder and TOMAS. The optimal paste quality was obtained by mixing $0.18 \mathrm{~g}$ PSAC and 0.12 g TOMAS corresponding to a ratio of 60:40 (\%). The constituents were thoroughly hand mixed in a $50 \mathrm{~mm}$ Petri dish to produce the optimal paste quality and then the paste was poured and packed into empty body of a glassy carbon electrode (5mm diameter) connected to the $\mathrm{pH} /$ ion meter by a thin copper wire to produce an electrical contact. The composite surface was polished on weighing paper until the surface displayed a shiny appearance. The surface was rinsed carefully with double-distilled water prior to each experiment. The electrode is stored in a desiccator when it is not in use to avoid adsorption of contaminants.

The potentiometric measurements were conducted as follows: The modified carbon paste electrode and reference electrode were placed in $50 \mathrm{~mL}$ of a stirred, $0.1 \mathrm{M} \mathrm{Cd}$ (II) solution until the potential reading was constant. The standard addition method was used to investigate the electrode response characteristics. Cadmium salt standard solutions were added so that the cadmium concentration ranged between $10^{-10}$ and $10^{-1} \mathrm{M}$. Pippette the suitable volume $(0.2-100 \mu \mathrm{L})$ of cadmium standards into a 50 $\mathrm{mL}$ water in measuring beaker and measure the potential in the appropriate way for the ion to be measured (i.e. with stirring and sufficient time for stable reading). The potential readings were recorded after each addition when stable values had been obtained. The concentration of solutions was checked by inductively couple plasma optical emission spectrometer ICP-OES.

The electrode potential of the electrochemical cell $\mathrm{E}_{\text {cell }}$ is described by the following Nernst equation:

$$
\left[\mathrm{E}_{\mathrm{cell}}=\mathrm{E}_{\mathrm{cons}}+2.303 \frac{R T}{z F} * \log a\right]
$$

where $\mathrm{E}_{\text {cons }}$ is a constant term (the sum of the standard potential and liquid junction potential), $\mathrm{R}$ is the ideal gas constant, $\mathrm{T}$ is the absolute temperature, $\mathrm{F}$ is the Faraday constant, $z$ is the charge of the ion, and $a$ is the activity of the ion. At low concentrations, the activity value $a$ can be replaced with the concentration value $C$. The prelogarithmic factor $2.303 \frac{R T}{z F}$ is obtained from the slop (S) of the plot of $E_{\text {cell }}$ versus $\log C$, and the equation becomes:

$$
\left[\mathrm{E}_{\mathrm{cell}}=\mathrm{E}_{\mathrm{cons}}+S \log C\right]
$$

Potentiometric selectivity of this electrode towards different cations was calculated with the matched potential method (MPM) [14].

In this method, the activity of Cd(II) was increased from $\mathrm{a}_{\mathrm{i}}=1.0 \times 10^{-5} \mathrm{M}$ (primary ion) to $\mathrm{a}_{\mathrm{i}}=5.0$ $\times 10^{-5} \mathrm{M}$, and the corresponding potential change $(\Delta \mathrm{E})$ was measured. Then a solution of an interfering ion $\left(\mathrm{a}_{\mathrm{j}}\right)$ in the concentration range of $1.0 \times 10^{-1}-1.0 \times 10^{-2} \mathrm{M}$ was added to a new primary ion $\left(\mathrm{a}_{\mathrm{i}}\right)$ until the same potential change $(\Delta \mathrm{E})$ was recorded. The selectivity factor, $\mathrm{k}_{\mathrm{ij}}{ }^{\text {pot }}$, was calculated for each interferent using the following equation:

$$
\left[k_{i j}^{p o t}=\left(a_{i}{ }^{\prime}-a_{i}\right) / a_{j}\right]
$$




\subsection{Analytical experiments}

In coordination with the staff of the Palestinian Water Authority, water samples were collected from four domestic wells nearest to the waste water collection area in the Gaza Strip (Palestine). To assure that the collected sample was from groundwater and not water standing in the well, it was originally proposed that the well should be pumped for at least 1-2 $\mathrm{h}$ prior to the collection of the sample. Approximately $500 \mathrm{~mL}$ of water for each sample was taken in laboratory certified clean bottles and labelled with the sample location, date, and time of sample collection. The sample was stored at $4{ }^{\circ} \mathrm{C}$ and shipped to Malaysia, where the heavy metal contents were analyzed by ICP-OES and the proposed ISEs.

\section{Results and Discussion}

In this study, improved versions of Cd(II) selective electrode using palm shell activated carbon based on task specific ionic liquids was prepared. Trioctylmethylammonium salicylate (TOMAS) in ion selective electrodes was investigated to fully understand their functions as both an ionophore and plasticizer in potentiometric sensors.

\subsection{Response of the Electrode}

The behaviour of potentiometric sensors with carbon paste electrode depends on the composition of the electrode material used and the condition of the contact solution. It is known that the response of an ion selective electrode depends not only on the nature and amount of an ionophore but also on the nature and the amount of the plasticizer. The influence of the plasticizer type and concentration on the characteristics of the studied cadmium electrode was investigated using eight plasticizers with different polarities, including DOA, DOP, TOPh, DOS, $\mathrm{BPh}, \mathrm{DBPh}, \mathrm{TBPh}$ and NPOE. Different plasticizer/PSAC/TOMAS (w/w) ratios were studied to determine the influence of the amount of plasticizer in the electrode. The obtained results are presented in Table 1. These results show that the potentiometric responses of the electrodes modified with conventional plasticizers were unsatisfactory, whereas those of the proposed electrode towards $\mathrm{Cd}$ (II) ions were greatly improved in the presence of TOMAS as both an ionophore and a plasticizer. The conventional plasticizer weakens the electrochemical response of the CPE and is especially disadvantageous for trace detection. Therefore, the use of the considerably viscous TOMAS ionic liquid, which is chemically inert and electrochemically conductive, as a pasting binder may be an ideal alternative for an improved paste electrode.

Several electrode compositions were investigated by varying the ratio of palm shell activated carbon and TOMAS for the systematic investigation of each paste composition. The particular $40 \mathrm{wt} \%$ of task specific ionic liquid composition typically used for the paste preparations demonstrates unique properties in terms of slope and $r^{2}$. In this regard, the use of a $40 \mathrm{wt} \%$ TOMAS/PSAC matrix is significant. The paste matrix composition should, therefore, be optimized with respect to other criteria such as structural integrity. The highest quality paste was obtained by mixing PSAC and TOMAS in a ratio of $60: 40(\%)$. 
Table 1. Composition and optimization of cadmium selective electrode

\begin{tabular}{ccccccc}
\hline No. & $\begin{array}{c}\text { TOMAS } \\
(\%)\end{array}$ & $\begin{array}{c}\text { PSAC } \\
(\%)\end{array}$ & $\begin{array}{c}\text { Plasticizer } \\
(\%)\end{array}$ & $\begin{array}{c}\text { working concentration } \\
\text { range }(\mathrm{M})\end{array}$ & $\begin{array}{c}\text { Slope } \\
\left(\mathrm{mV} \mathrm{dec}^{-1}\right)\end{array}$ & $\mathrm{R}^{2}$ \\
\hline 1 & 40 & 60 & 0 & $1.0 \times 10^{-9}$ to $1.0 \times 10^{-2}$ & 30.90 & 0.99 \\
2 & 10 & 50 & $40(\mathrm{NPOE})$ & $1.0 \times 10^{-7}$ to $1.0 \times 10^{-2}$ & 27.46 & 0.85 \\
3 & 10 & 50 & $40(\mathrm{DOP})$ & $1.0 \times 10^{-7}$ to $1.0 \times 10^{-2}$ & 27.31 & 0.82 \\
4 & 10 & 50 & $40(\mathrm{DOS})$ & $2.5 \times 10^{-7}$ to $1.0 \times 10^{-2}$ & 26.10 & 0.74 \\
5 & 10 & 50 & $40(\mathrm{DOA})$ & $2.5 \times 10^{-7}$ to $1.0 \times 10^{-2}$ & 26.29 & 0.81 \\
6 & 10 & 50 & $40(\mathrm{BPh})$ & $1.0 \times 10^{-6}$ to $1.0 \times 10^{-2}$ & 44.85 & 0.79 \\
7 & 10 & 50 & $40(\mathrm{DBPh})$ & $1.0 \times 10^{-6}$ to $1.0 \times 10^{-2}$ & 20.70 & 0.72 \\
8 & 10 & 50 & $40(\mathrm{TBPh})$ & $1.0 \times 10^{-6}$ to $1.0 \times 10^{-2}$ & 38.92 & 0.75 \\
9 & 10 & 50 & $40(\mathrm{TOPh})$ & $1.0 \times 10^{-6}$ to $1.0 \times 10^{-2}$ & 23.38 & 0.75 \\
\hline
\end{tabular}

The calibration for the developed electrode over a wide range of $\mathrm{Cd}(\mathrm{II})$ solution activities is shown in Fig. 2. The slope of the calibration curve $(30.9 \mathrm{mV} / \mathrm{dec})$ is close to the curve that is predicted $(29.5$ $\mathrm{mV} / \mathrm{dec}$ for bivalent cation) by the Nernst equation, indicating that the electrode was sensitive to $\mathrm{Cd}(\mathrm{II})$ over a wide range of activities $\left(1 \times 10^{-9}-1 \times 10^{-2} \mathrm{M}\right)$.

Figure 2. Calibration curve for palm shell activated carbon paste electrode based on TOMAS over a wide range of solution $\mathrm{Cd}(\mathrm{II})$.

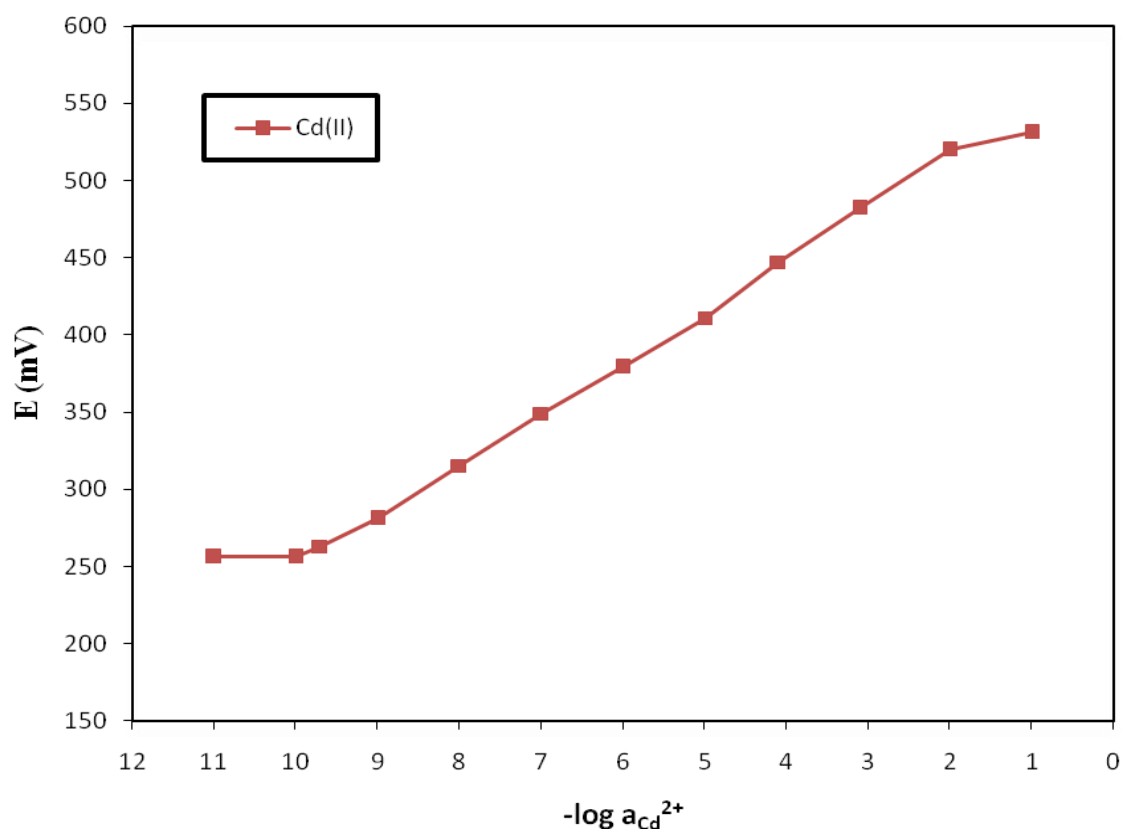


In addition, the electrode showed a linear response over this range of activities, with a departure from linearity (i.e., a loss of sensitivity) at activities lower than $10^{-9} \mathrm{M} \mathrm{Cd}(\mathrm{II})$.

The unique sensitivity and selectivity towards $\mathrm{Cd}$ (II) obtained for a given electrode depends on the coordinate interaction between TOMAS and the $\mathrm{Cd}$ (II) ion, which may be explained by the chelating effect of the ortho-positioned carboxylate group on the TOMAS molecule on the palm shell activated carbon, in addition to the known formation of metal-hydroxlates [15].

TOMAS which was used as the solvent mediator and plasticizer, has certain desirable properties and characteristics, such as high lipophilicity, high molecular weight, and low vapour pressure. Additionally, its viscosities and dielectric constants was adequate for the construction of an ion selective electrode with desirable analytical properties, such as selectivity, sensitivity, fast response, and long lifetime. The critical response characteristics of the proposed electrode were evaluated according to IUPAC recommendations [16].

\subsection{Effect of $p H$ on electrodes response}

The $\mathrm{pH}$ of each solution was verified, and its effect on the electrode potential at various metal concentrations was studied. For this purpose, several $\mathrm{Cd}(\mathrm{II})$ concentrations $\left(1.0 \times 10^{-6} \mathrm{M}, 1.0 \times 10^{-4} \mathrm{M}\right.$ and $1.0 \times 10^{-3} \mathrm{M}$ ) were prepared, and the potential variations of the electrode over a $\mathrm{pH}$ range of 1-12 were followed. The $\mathrm{pH}$ was adjusted by adding small volumes of hydrochloric acid $(1 \mathrm{M})$ and/or sodium hydroxide $(2 \mathrm{M})$ to the sample solution.

The obtained results are shown in Fig. 3. It can be seen that the electrode potential remain almost constant in the $\mathrm{pH}$ range of 4-9. The change in potential at higher $\mathrm{pH}$ values may be due to the formation of hydroxy complexes of $\mathrm{Cd}$ (II) [17]. At lower $\mathrm{pH}$ values, a sharp decrease in the electrode response is observed; this result is due to the protonation of carboxylic groups on the TOMAS molecule.

Figure 3. Effect of $\mathrm{pH}$ on the potential response of $\mathrm{Cd}(\mathrm{II})$ palm shell activated carbon paste electrode.

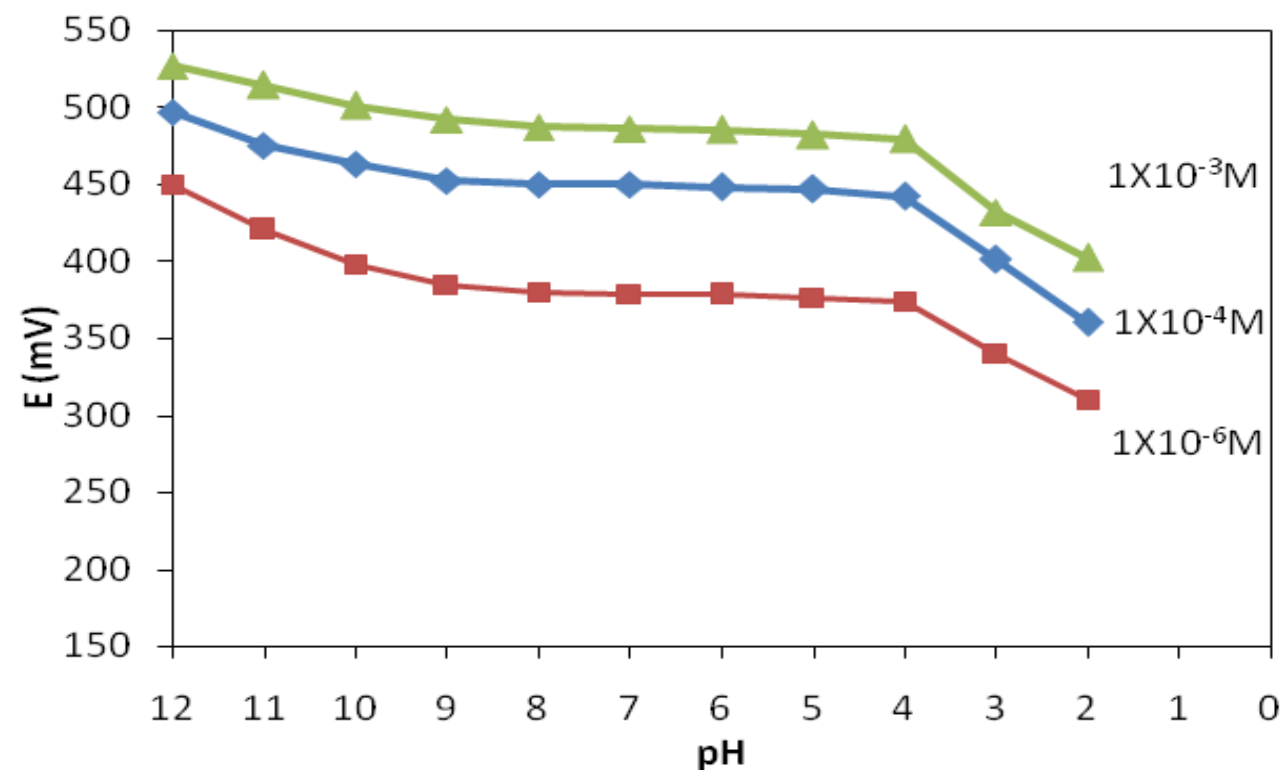




\subsection{Potentiometric selectivity coefficients}

It is well known that the selectivity behaviour of an electrode is one of the most important factors in its evaluation, which is measured in terms of the selectivity coefficient. The selectivity coefficient not only depends on ion charge and concentration, but it can also be affected by the type of interaction between the ion and the ionophore. The selectivity factor, $\log \mathrm{k}^{\mathrm{pot}}$ is a measure of the preference of ion selective electrode for interfering ion relative to the primary ion to be measured. A selectivity factor $\log \mathrm{k}^{\text {pot }}$ below 1 indicates that the preference is for the primary ion.

Table 2 show that the electrode exhibited better selectivity for the cadmium (II) ion over a wide variety of other metal ions. The values of the selectivity coefficients, listed in Table 2, reflect a very high selectivity of this electrode for cadmium (II) ion over most of the tested species. $\mathrm{Hg}^{2+}$ and $\mathrm{Fe}^{2+}$ caused only slight interference. However, they do not cause any interference at low concentration. This phenomenon suggests a high stability of the complex between cadmium and TOMAS.

Table 2. Selectivity coefficient values of various interfering ions with $\mathrm{Cd}(\mathrm{II})$ selective electrodes based on TOMAS using matched potential method (MPM).

\begin{tabular}{llll}
\hline Interferent ion, $\mathrm{j}$ & $-\log \mathrm{kpotCd}^{2+}, \mathrm{j}$ & Interferent ion, $\mathrm{j}$ & $-\log \mathrm{kpotCd}^{2+}, \mathrm{j}$ \\
$\mathrm{Cu}^{2+}$ & 3.26 & $\mathrm{Na}^{+}$ & 4.71 \\
$\mathrm{Hg}^{2+}$ & 2.47 & $\mathrm{~K}^{+}$ & 4.54 \\
$\mathrm{Ca}^{2+}$ & 3.95 & $\mathrm{Ni}^{2+}$ & 3.29 \\
$\mathrm{Mg}^{2+}$ & 4.15 & $\mathrm{Cr}^{3+}$ & 4.21 \\
$\mathrm{Zn}^{2+}$ & 3.83 & $\mathrm{Co}^{2+}$ & 3.37 \\
$\mathrm{Al}^{3+}$ & 3.74 & $\mathrm{Ag}^{+}$ & 3.10 \\
$\mathrm{Fe}^{3+}$ & 2.98 & $\mathrm{~Pb}^{2+}$ & 4.02 \\
\hline
\end{tabular}

The selectivity sequence of the employed modified CPE for different inorganic cations approximately obeys the order: $\mathrm{Hg}^{2+}>\mathrm{Fe}^{3+}>\mathrm{Ag}^{+}>\mathrm{Cu}^{2+}>\mathrm{Ni}^{2+}>\mathrm{Co}^{2+}>\mathrm{Al}^{3+}>\mathrm{Zn}^{2+}>\mathrm{Ca}^{2+}$ $>\mathrm{Pb}^{2+}>\mathrm{Mg}^{2+}>\mathrm{Cr}^{3+}>\mathrm{K}^{+}>\mathrm{Na}^{+}$.

It is worth mentioning that TOMAS has excellent selectivity for the $\mathrm{Cd}$ (II) ions over other metal ions; this selectivity may be due to the design of TOMAS to contain negatively charged O-donor groups that enhance its complexing ability for the $\mathrm{Cd}$ (II) ion over other metals. Here, it is critical to note the existence of a rule of ligand design that permits fairly predictable control of selectivity on the basis of metal ion size. Ionic radius is an important parameter in the formation and stability of metal complexes [18]. Moreover, Cd(II) (ionic radii 0.97 $\AA$ ) ions show a strong tendency towards ligands with donating atoms of hard character, such as $\mathrm{N}$ and $\mathrm{O}$. However, it is clear that more work needs to 
be performed in this area to establish the relative coordinating abilities of TOMAS to a variety of metal ions of different types and sizes.

To investigate the effect of counter ions on the potential response of the electrode, cell potentials were measured using constant concentrations of $\mathrm{Cd}\left(\mathrm{NO}_{3}\right)_{2}, \mathrm{CdCl}_{2}$ and $\mathrm{CdSO}_{4}$ under the same experimental conditions. It was found that in $1.0 \times 10^{-4} \mathrm{M}$ solutions of different counter ions, the values of electrode potential were the same $(449 \mathrm{mV})$, indicating a negligible influence of counter ions on the response behaviour of the electrode.

\subsection{Dynamic response time}

The response time of the electrode is one of the most important characteristics of the ion selective electrode. The IUPAC definition of the response time has changed over time [16,19,20]. According to IUPAC recommendations, the response time of an ion selective electrode is defined as the time between the addition of the analyte to the sample solution and the time when limiting potential has reached its steady state value within $1 \pm \mathrm{mV}$. In this study, the response time of the electrode was tested by measuring the time required to achieve a steady state potential (within $1 \pm \mathrm{mV}$ of the final equilibrium value) after successive immersion in a series of $\mathrm{Cd}(\mathrm{II})$ ions. The results, shown in Fig. 4 indicate that the response time of the electrodes was approximately 10 s for the solution of cadmium ion in the concentration range of $1 \times 10^{-8}-1 \times 10^{-4} \mathrm{M}$. This result is probably due to the fast complexation of $\mathrm{Cd}(\mathrm{II})$ ions by the TOMAS molecule dispersed in the palm shell activated carbon paste matrix.

Figure 4. Response time of the electrode obtained by successive increase of $\mathrm{Cd}(\mathrm{II})$ ion concentrations.

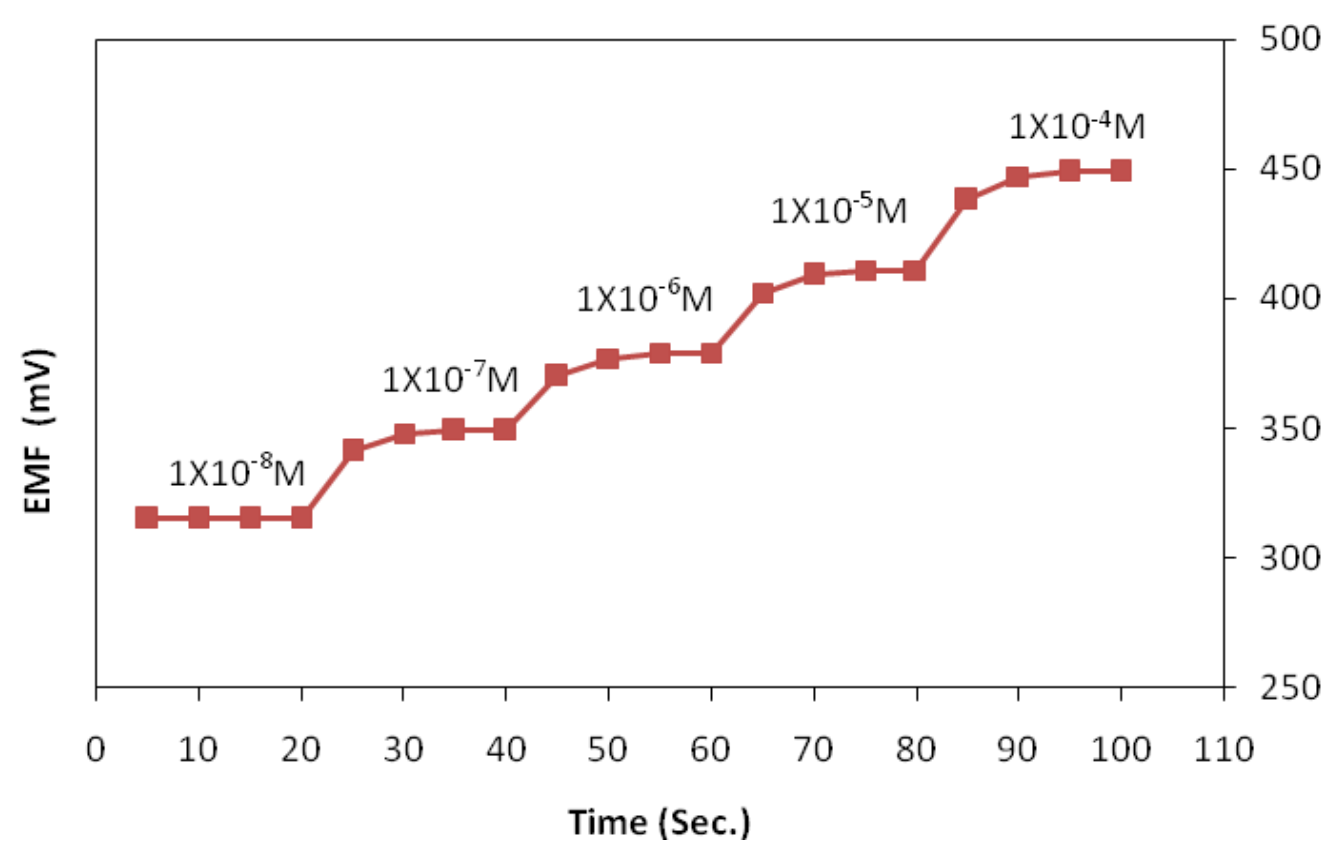

\subsection{Electrodes life time}

The life time of the electrode depends on the distribution coefficient of the electrode compositions between the aqueous phase and the electrode phase. Accordingly, the life time of the electrode must depend on the electrode components. 
In this work, the life time of the electrode was determined by performing periodic calibrations with standard solutions and calculating the slopes over $\mathrm{Cd}$ (II) ion concentration ranges of $1 \times 10^{-9}$ to $1 \times 10^{-}$ ${ }^{2} \mathrm{M}$. The obtained results showed that the present electrode had a lifetime of over 70 days (Table 3 ). During this time, the detection limit of the electrode remained almost constant, and the slope of the electrode response decreases from 30.9 to $28.03 \mathrm{mV}$ per decade. Therefore, the electrode can be used for at least two months without a considerable change in its response characteristic towards $\mathrm{Cd}(\mathrm{II})$ ions, which may be due to the stability of TOMAS on palm shell activated carbon.

Additionally, the solubility of TOMAS in water is approximately $2.0 \pm 0.2 \times 10^{-4} \mathrm{M}$ [13], which significantly decreases the possibility of the electrode components leaching into the solution.

Table 3. Cadmium electrode response during 70 days

\begin{tabular}{lll}
\hline Time period & Slope & Limit of Detection $(\mathrm{M})$ \\
$($ day $)$ & $(\mathrm{mV} /$ decade $)$ & \\
\hline 1 & 30.90 & $1 \times 10^{-10}$ \\
7 & 30.90 & $1 \times 10^{-10}$ \\
20 & 30.85 & $1 \times 10^{-10}$ \\
30 & 29.38 & $1 \times 10^{-10}$ \\
50 & 28.21 & $1 \times 10^{-9}$ \\
70 & 28.03 & $1 \times 10^{-9}$ \\
\hline
\end{tabular}

\subsection{Scanning electron microscopy studies}

Surface morphology plays a significant role in determining the surface availability of activated carbon. Scanning electron microscopy was used to observe the surface morphology at high resolution and to study the variation in surface texture. Figure 5 shows the typical morphological features of palm shell activated carbon paste electrode based on TOMAS using scanning electron microscopy (SEM). The pure PSAC surface (Figure 5a) has good porosity and smooth surfaces with long linear ridges and rough surfaces with oval ridges and micropores. Figure 5b shows the SEM images of the paste films based on TOMAS. As shown, the active TSIL on the paste films are more uniformly distributed across the electrode surface with good homogeneity. The reproducibility of the electrode surface is usually improved by the homogeneous placement of the active TSIL. The best results are obtained when the components are well mixed into the carbon paste preparation. Significant differences in the initial surface structure of the paste and the paste surface after it was dipped in a $1 \times 10^{-4} \mathrm{M}$ metal solution for $30 \mathrm{~min}$ are seen. SEM micrographs obtained at the same magnifications indicate significant improvement in the microstructure of the proposed electrode. It can be seen that after binding the TOMAS with Cd (II), the morphology changes. Aggregates of white needles were observed on the 
surface (Figure 5c), which were presumably complexes formed between the TOMAS and the cadmium ions.

Figure 5. SEM images of (a) Pure PSAC, (b) PSAC paste electrode based on TOMAS and (c) PSAC paste electrode surface after it was dipped in $1 \times 10^{-4} \mathrm{M} \mathrm{Cd}(\mathrm{II})$
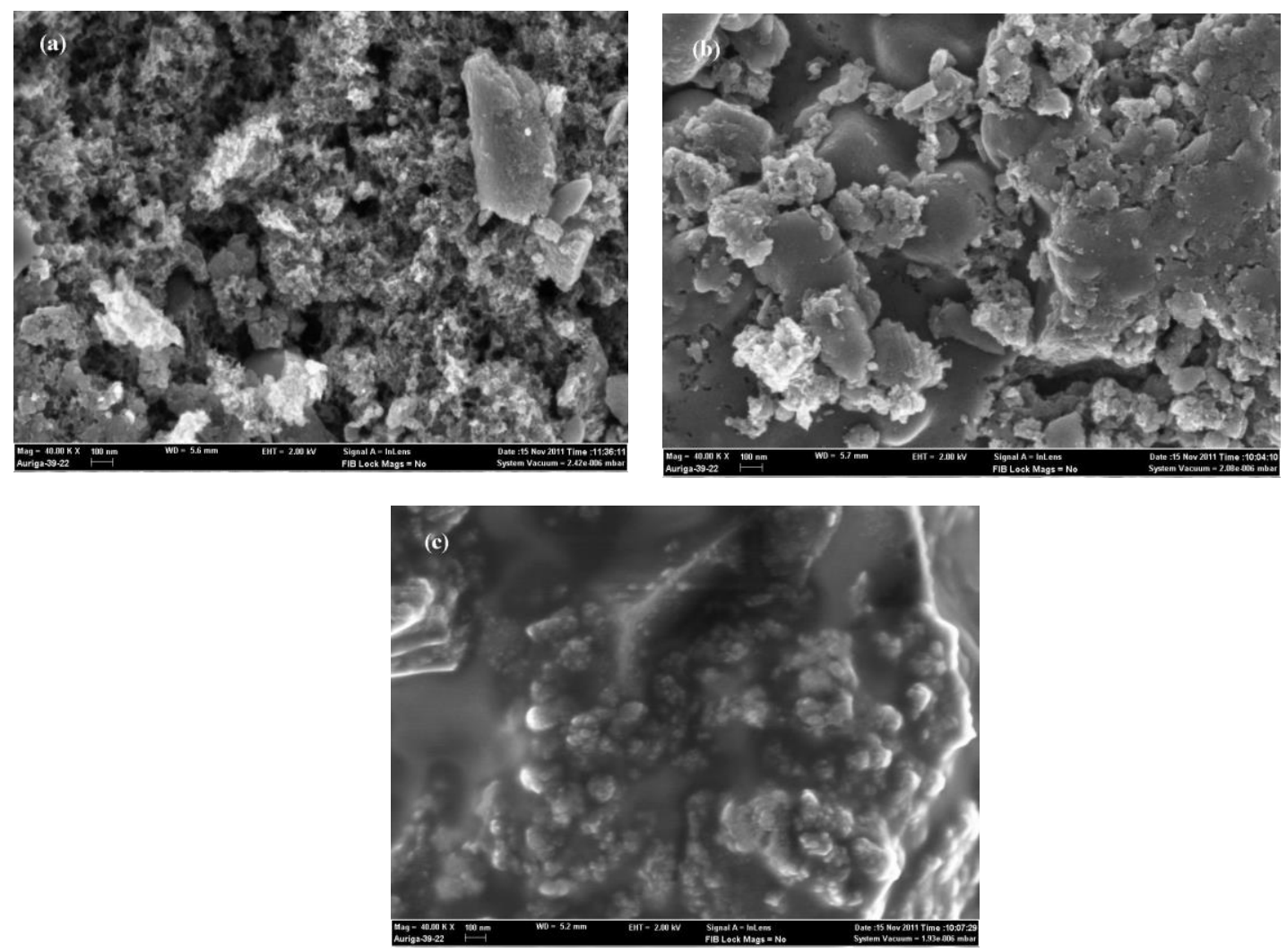

\subsection{Energy dispersive X-ray analysis (EDAX)}

EDAX analysis was employed to confirm the presence of TOMAS and cadmium ions on the surface of PSAC. The corresponding EDAX spectrum and the composition table are shown in Figure 6. From Figure (6a), in the case of virgin palm shell activated carbon, the characteristic peaks of oxygen is smaller to its peak in Figure (6b), this result indicates that TOMAS was impregnated at the PSAC. Based on figure (6c), a significant amount of cadmium is present in the sample and is uniformly distributed, whereas in figure (6d), the amount of cadmium is less than that in figure (6c). The results show that cadmium becomes the principal element of the modified palm shell activated carbon surface. This was due to the fact that cadmium ions were chemisorbed on the surface of modified palm shell activated carbon, whereas the cadmium ions were physisorbed on the surface of virgin palm shell activated carbon. Therefore, EDAX analysis provides direct evidence for the specific adsorption of cadmium ions onto the surface of modified palm shell activated carbon. 
Figure 6. EDAX spectrum of palm shell activated carbon: (a) Virgin palm shell activated carbon, (b) Palm shell activated carbon modified with TOMAS, (c) palm shell activated carbon modified with TOMAS adsorbed with cadmium and (d) Virgin palm shell activated carbon adsorbed with cadmium.
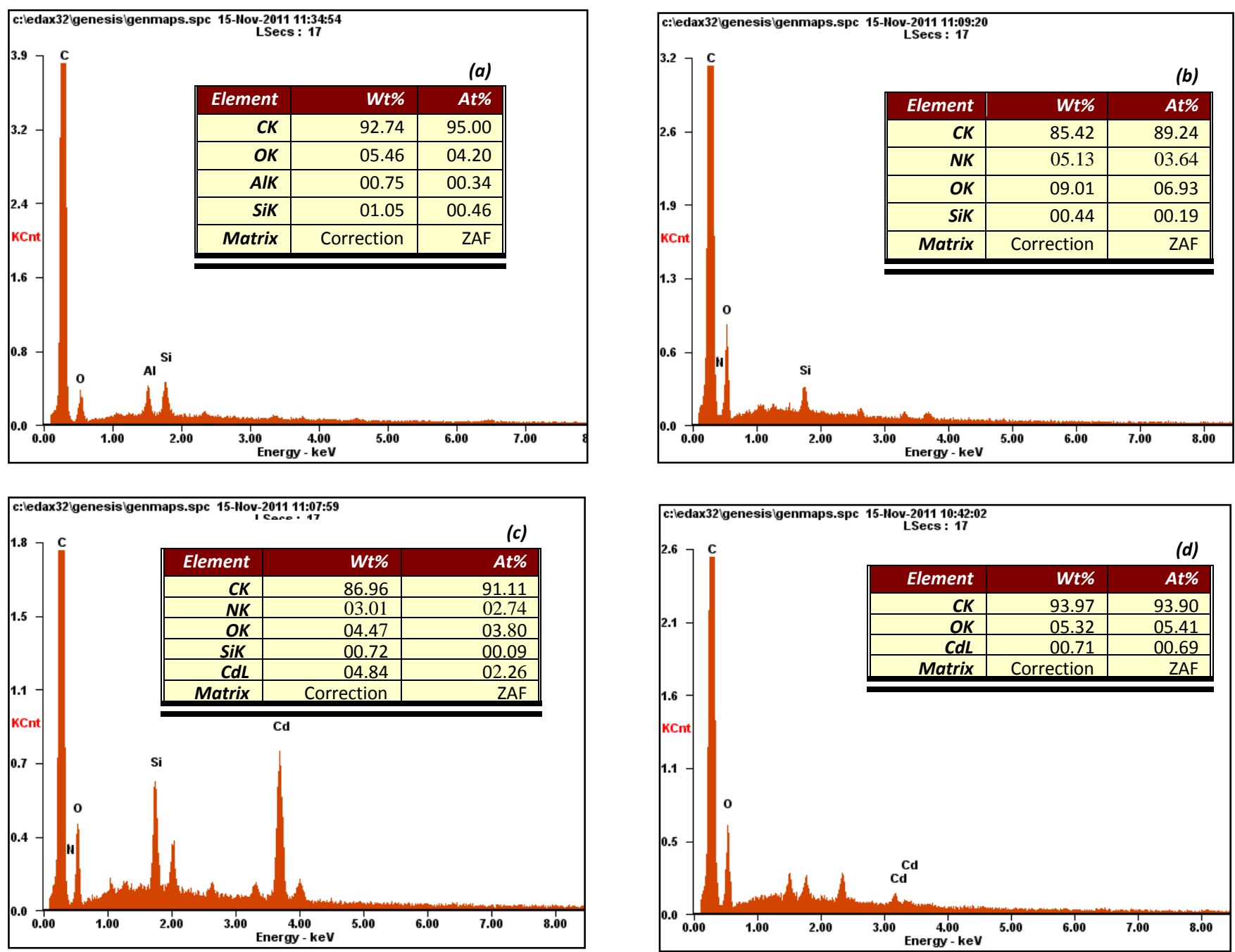

\subsection{Analytical applications}

The proposed electrode has been mainly used in the determination of the amount of cadmium (II) ions in water samples.

Water samples were collected from four domestic wells nearest to the waste water collection area in the Gaza Strip (Palestine).

Statistical treatment of analytical applications results: One of the most important properties of a new analytical method is that it should be free from systematic error, where, the value obtained, after its application, should be very close to the true value. This property may be tested by applying the method to a standard sample. However, random errors make it most unlikely that the measured amount even if there were no systematic error. This comparison between the obtained and the expected values is expressed mathematically in what is called the recovery values. In this work $\mathrm{Cd}(\mathrm{II})$ contents measured by the proposed electrode were compared with those obtained by ICP-OES (Table 4). Almost 100\% recovery was calculated for each of the applications in this work, high precision was observed as 
indicated by the very low standard deviation values. These results show that $\mathrm{Cd}(\mathrm{II})$ concentrations obtained with the proposed electrode were similar to those obtained by ICP with deviations below $4 \%$ for all samples. These values reflect high accuracy and precision of the proposed electrode.

Table 4. Potentiometric determination of $\mathrm{Cd}(\mathrm{II})$ in water samples using the proposed electrode and ICP.

\begin{tabular}{lllll}
\hline \multicolumn{5}{c}{ Cd (II) $\left(\mathbf{m g L}^{-1}\right)^{\mathbf{b}}$} \\
& Proposed & ICP & RSD\% & Recovery\% \\
Sample $^{\mathbf{a}}$ & electrode & & & \\
\hline$(1)$ & 0.575 & 0.55 & 3.19 & 104.6 \\
$(2)$ & 0.464 & 0.446 & 2.90 & 104.2 \\
$(3)$ & 0.480 & 0.491 & 1.55 & 97.8 \\
(4) & 0.423 & 0.412 & 1.92 & 102.8 \\
\hline
\end{tabular}

a From some ground water wells in Gaza Strip.

$b$ Mean data for three replicate measurements.

3.9 Comparison of the response for the proposed $C d(I I)$ selective electrodes with other reported electrodes

The comparative study of the proposed electrode with some recently developed cadmium electrode is summarised in Table 5. The results show the superiority of the proposed electrode in terms of its wider linear range, Nernstian slope, and lower detection limit. 
Table 5. Comparison of the proposed Cd-PSACPE electrode with previously reported electrodes.

\begin{tabular}{|c|c|c|c|c|c|}
\hline Ionophore & $\begin{array}{l}\text { Slope } \\
\text { (mV/decade) }\end{array}$ & $\begin{array}{l}\text { Linear range } \\
\left(\operatorname{mol~L}^{-1}\right)\end{array}$ & $\begin{array}{l}\text { Detection limit } \\
\left(\operatorname{mol~L}^{-1}\right)\end{array}$ & Response time (s) & Ref. \\
\hline 4-hydroxy salophen & $30.1 \pm 1$ & $1.0 \times 10^{-6}-1.0 \times 10^{-1}$ & $8.4 \times 10^{-7}$ & 20 & [17] \\
\hline $\begin{array}{l}\mathrm{N}, \mathrm{N}_{-}-[\text {bis(pyridin-2-yl) } \\
\text { formylidene]butane-1,4-diam }\end{array}$ & 30 & $7.9 \times 10^{-8}-1.0 \times 10^{-1}$ & $5.0 \times 10^{-8}$ & 10 & {$[21]$} \\
\hline dicyclohexano-24-crown-8 & $30.0 \pm 1.0$ & $3.0 \times 10^{-5}-1.0 \times 10^{-1}$ & - & 23 & {$[22]$} \\
\hline 3,5-Dinitro-N-(tri-2-pyridyl & $30 \pm 1$ & $2.16 \times 10^{-7}-1.00 \times 10^{-1}$ & $1.82 \times 10^{-7}$ & 50 & {$[23]$} \\
\hline \multicolumn{6}{|l|}{ methyl) benzamide } \\
\hline tetrathia-12-crown-4 & $29 \pm 1$ & $4.0 \times 10^{-7}-1.0 \times 10^{-1}$ & $1.0 \times 10^{-7}$ & $<10$ & {$[24]$} \\
\hline $\begin{array}{l}\mathrm{N}, \mathrm{N}, \mathrm{N}^{\prime}, \mathrm{N}^{\prime} \text {-tetradodecyl-3,6- } \\
\text { dioxaoctanedithioamide (ETH }\end{array}$ & 29.6 & $1.0 \times 10^{-7}-1.0 \times 10^{-4}$ & $1.0 \times 10^{-10}$ & - & {$[25]$} \\
\hline TOMAS & $30.90 \pm 1$ & $1.0 \times 10^{-9}-1.0 \times 10^{-2}$ & $1.0 \times 10^{-10}$ & 10 & This work \\
\hline
\end{tabular}




\section{Conclusions}

As indicated by this work, the use of TSIL in electrochemical sensing is a promising and exciting area of research that definitely merits further exploration. The combination of TSILs with electrochemical sensors has the potential to broaden or even revolutionize the range of analytical methods.

The mechanism of generation of the electrode potential may involve different processes. The electrode potential is created via surface chemisorption; i.e., the electrode potential is produced by a surface reaction. The reaction centres can be complex formation groups. From the results obtained in the present work, we have proved that the deciding role in the mechanism of the electrode potential generation play the surface phenomena-chemisorption, taking place at the interface between the electrode and the solution, and formation of salicylate complexes. We implies that IL serves as a complexing reagent itself due to a presence of appropriate functionalities in either cationic or anionic component. Typically, TSILs bear complexing groups in anionic (salicylate -based) part. Many salicylate are known to strongly bind metal ions.

The results presented herein demonstrate the utility of TSIL as both plasticizers and ionophores in the preparation of new ion selective electrodes for the determination of heavy metal ions.

In this work, palm shell activated carbon modified with trioctylmethylammonium salicylate (TOMAS) was used for the potentiometric determination of cadmium ions in water samples, yielding the following important findings:

Palm shell activated carbon modified with TOMAS enhances the potentiometric characters and enlarges the active surface area at the proposed electrode.

More importantly, this work is the first to demonstrate that TSILs can have dual functions, acting as an ionophore and plasticizer. This finding will likely have a strong impact on potentiometric sensor technology because ionophores and plasticizers are usually different materials.

$>$ The proposed electrode shows excellent potentiometric response, sensitivity, selectivity, stability, and satisfactory reproducibility.

$>$ The experiment indicates that the proposed electrode is able to directly monitor the cadmium ion concentration without requiring a separation process or disturbing the binding equilibrium.

\section{Acknowledgements}

This work was carried at the Center for Separation Science and Technology and was financed through the High Impact Research Grant Project No. UM.C/HIR/MOHE/ENG/43. 


\section{Author Contributions}

This work reports original results pertaining to the detection in aqueous solutions of a hazardous pollutant namely cadmium. This topic fits well with the scope of the journal. We are confident that this article will generate a significant number of citations since it deals with an area of current and future great interest namely the application of Ionic Liquid for the detection of pollutants. To the best of our knowledge, this study is the first to propose this electrochemical sensor, based on a task specific ionic liquids carbon paste electrode, to detect cadmium ions in aqueous solution. The TSILs has dual functions as ionophore and plasticizer. This will likely have a strong impact on potentiometric sensor technology because ionophores and plasticizers are usually different materials.

\section{Conflicts of Interest}

The authors declare no conflict of interest.

\section{References}

1. WHO. Guidelines for drinking water quality. Third ed.; World Health Organization: Geneva, 2004; Vol. 1, p 317.

2. Sochor, J.; Zitka, O.; Hynek, D.; Jilkova, E.; Krejcova, L.; Trnkova, L.; Adam, V.; Hubalek, J.; Kynicky, J.; Vrba, R., et al. Bio-sensing of cadmium(ii) ions using staphylococcus aureus. Sensors 2011, 11, 10638-10663.

3. Afkhami, A.; Madrakian, T.; Siampour, H. Flame atomic absorption spectrometric determination of trace quantities of cadmium in water samples after cloud point extraction in triton X-114 without added chelating agents. Journal of Hazardous Materials 2006, 138, 269272.

4. Li, S.; Cai, S.; Hu, W.; Chen, H.; Liu, H. Ionic liquid-based ultrasound-assisted dispersive liquid-liquid microextraction combined with electrothermal atomic absorption spectrometry for a sensitive determination of cadmium in water samples. Spectrochimica Acta Part B: Atomic Spectroscopy 2009, 64, 666-671.

5. Guo, W.; Hu, S.; Xiao, Y.; Zhang, H.; Xie, X. Direct determination of trace cadmium in environmental samples by dynamic reaction cell inductively coupled plasma mass spectrometry. Chemosphere 2010, 81, 1463-1468.

6. Wen, X.; Wu, P.; Xu, K.; Wang, J.; Hou, X. On-line precipitation-dissolution in knotted reactor for thermospray flame furnace aas for determination of ultratrace cadmium. Microchemical Journal 2009, 91, 193-196. 
7. Yang, G.; Hu, Q.; Huang, Z.; Yin, J. Study on the determination of lead, cadmium, mercury, nickel and zinc by a rapid column high-performance liquid chromatography. Journal of the Brazilian Chemical Society 2005, 16, 1154-1159.

8. James, H.D. Task-specific ionic liquids. Chemistry Letters 2004, 33, 1072-1077.

9. Olivier-Bourbigou, H.; Magna, L. Ionic liquids: Perspectives for organic and catalytic reactions. Journal of Molecular Catalysis A: Chemical 2002, 182-183, 419-437.

10. Hapiot, P.; Lagrost, C. Electrochemical reactivity in room temperature ionic liquids. Chemical Reviews 2008, 108, 2238-2264.

11. Peng, B.; Zhu, J.; Liu, X.; Qin, Y. Potentiometric response of ion-selective membranes with ionic liquids as ion-exchanger and plasticizer. Sensors and Actuators B: Chemical 2008, 133, 308-314.

12. Shomar, B. Water and wastewater in gaza strip: Environmentally as hot as politically. Z. Geol. Wiss. 2007, 35, 165-176.

13. Egorov, V.M.; Smirnova, S.V.; Pletnev, I.V. Highly efficient extraction of phenols and aromatic amines into novel ionic liquids incorporating quaternary ammonium cation. Separation and Purification Technology 2008, 63, 710-715.

14. Gadzekpo, V.P.Y.; Christian, G.D. Determination of selectivity coefficients of ion-selective electrodes by a matched-potential method. Analytica Chimica Acta 1984, 164, 279-282.

15. Alizadeh, T.; Ganjali, M.R.; Nourozi, P.; Zare, M.; Hoseini, M. A carbon paste electrode impregnated with cd2+ imprinted polymer as a new and high selective electrochemical sensor for determination of ultra-trace cd2+ in water samples. Journal of Electroanalytical Chemistry 2011, 657, 98-106.

16. Buck, R.P.; Lindner, E. Recommendations for nomenclature of ion selective electrodes. Pure and Applied Chemistry 1994, 66, 2527-2536.

17. Ensafi, A.A.; Meghdadi, S.; Sedighi, S. Sensitive cadmium potentiometric sensor based on 4hydroxy salophen as a fast tool for water samples analysis. Desalination 2009, 242, 336-345.

18. Hancock, R.D.; Martell, A.E. Ligand design for selective complexation of metal ions in aqueous solution. Chemical Reviews 1989, 89, 1875-1914.

19. Couto, C.; Montenegro, M. Potentiometric detectors for flow injection analysis systems, evolution and application. Quim. Nova 2000, 23, 774-784. 
20. Buck, R.P.; Cosofret, V. Recommended procedures for calibration of ion-selective electrodes. Pure and Applied Chemistry 1993, 65, 1849-1858.

21. Gupta, V.K.; Singh, A.K.; Gupta, B. Schiff bases as cadmium(ii) selective ionophores in polymeric membrane electrodes. Analytica Chimica Acta 2007, 583, 340-348.

22. Gupta, V.K.; Jain, A.K.; Kumar, P. Pvc-based membranes of dicyclohexano-24-crown-8 as cd(ii) selective sensor. Electrochimica Acta 2006, 52, 736-741.

23. Abbastabar-Ahangar, H.; Shirzadmehr, A.; Marjani, K.; Khoshsafar, H.; Chaloosi, M.; Mohammadi, L. Ion-selective carbon paste electrode based on new tripodal ligand for determination of cadmium (ii). Journal of Inclusion Phenomena and Macrocyclic Chemistry 2009, 63, 287-293.

24. Shamsipur, M.; Mashhadizadeh, M.H. Cadmium ion-selective electrode based on tetrathia-12crown-4. Talanta 2001, 53, 1065-1071.

25. Ion, A.C.; Bakker, E.; Pretsch, E. Potentiometric cd2+-selective electrode with a detection limit in the low ppt range. Analytica Chimica Acta 2001, 440, 71-79. 